\title{
Self Heated Thermo-Resistive Element Hot Wire Anemometer
}

\author{
Richard Jozef Adamec and David Victor Thiel
}

\begin{abstract}
A microelectromechanical systems (MEMS) hot wire anemometer consisting of thermoresistive elements arranged in a differential bridge configuration is presented. The excitation of the elements to the point of self heating allows for dedicated heating elements to be omitted from the device without compromising operation or accuracy.

Overall power consumption gives air velocity, and the temperature differential of each element pair is used for wind direction calculation and has demonstrated a sensing resolution better than $1 \%$ and a repeatability better than $2 \%$.
\end{abstract}

Index Terms-Anemometer, hot-wire, microelectromechanical systems (MEMS).

\section{INTRODUCTION}

A bulk machined dual axis hot wire anemometer consisting of four thermoresistive elements arranged in a differential bridge configuration is presented. Where heating elements are often used on such devices [1], the sensor discussed here uses self heating of the thermoresistive sensing elements to provide the thermal energy required to generate the thermal plume and temperature differential across the surface of the device.

The central heating elements used on typical integrated hotwire anemometers [2]-[4] use valuable real estate on the die and adds complexity and potential failure mechanisms to the design. Removal of the central heating element(s) reduces the number of elements that must be interfaced and frees up silicon real estate for other purposes, such as other sensing arrays [5].

The thermoresistive elements reported here are arranged to serve dual purposes as both the thermal sensing elements and the heating elements used to create the elevated surface temperature. The arrangement of the elements allows for dedicated heating elements to be omitted from the device without compromising operation or sacrificing accuracy. With the elimination of the central heating element(s) typically used, the element count is reduced to only four elements for the dual axis device compared to typical 5 or 8 element designs [6], [7]. Power consumption is also reduced along with an improvement in time response compared to some, more conventional, designs [8], [9].

Thermal and electrical power requirements are minimized by patterning the Nickel serpentine elements on a $1 \mu \mathrm{m}$ bulk machined Silicon Nitride membrane that provides thermal isolation from the surrounding Silicon substrate (Fig. 1).

Manuscript received April 30, 2009; revised October 08, 2009; accepted October 08, 2009. Current version published March 10, 2010. The associate editor coordinating the review of this paper and approving it for publication was Prof. Evgeny Katz.

The authors are with School of Engineering, Griffith University, Queensland, 4215 Australia (e-mail: r.adamec@griffith.edu.au; radamec@bigpond.net.au; d.thiel@griffith.edu.au).

Color versions of one or more of the figures in this paper are available online at http://ieeexplore.ieee.org.

Digital Object Identifier 10.1109/JSEN.2009.2035518

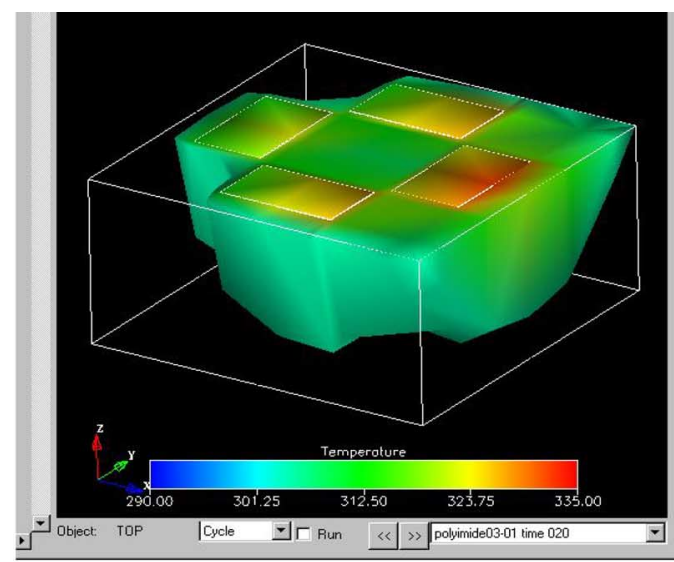

(a)

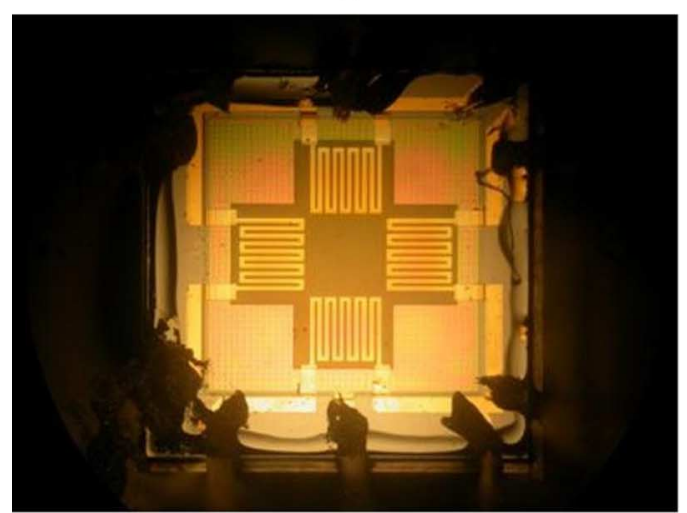

(b)

Fig. 1. Four element self heating sensor array. (a) FEM simulations showing isotherms within the $\mathrm{Si}_{3} \mathrm{~N}_{4}$ membrane. (b) Photomicrograph of a fabricated sensor.

Velocity information is extracted from the overall electrical power consumption of the four elements that are heated simultaneously from a common supply. Simultaneous solution of the temperature differential of opposing element pairs was used to determine the incident airflow direction and has demonstrated a sensing resolution less than $1 \%$ and a repeatable accuracy better than $2 \%$ for correctly dimensioned devices.

Field trials of these sensors have confirmed and demonstrated a reliable and robust design with exposure of the sensor surface to the environment including exposure to rain, dust and debris for periods in excess of 12 months with continuing operation.

\section{DATA AND RESULTS}

Power consumption for the device was $50 \mathrm{~mW}$ at $25^{\circ} \mathrm{C}$ for $0 \mathrm{~m} / \mathrm{s}$ wind velocity. Under these conditions the constant voltage supply to the heating elements achieved an above ambient temperature of $45^{\circ} \mathrm{C}$ to give an absolute element temperature of $70{ }^{\circ} \mathrm{C}$. Temperature differentials seen as the device was rotated in a wind tunnel reached a peak of $15^{\circ} \mathrm{C}$ between opposing elements. 


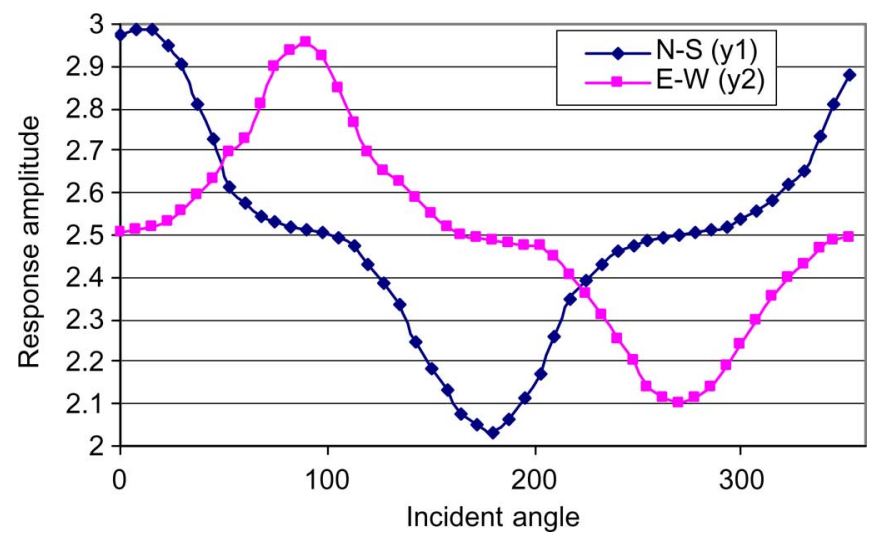

Fig. 2. Excessive element separation distances lead to an approximate sine $^{3}$ and $\operatorname{cosine} \mathrm{e}^{3}$ response as a reduction of sensitivity is introduced at angles perpendicular to the particular axis (actual recorded response).

Too much separation between elements or elements being too narrow leads to insensitivity at angles perpendicular to each axis and to distortion of the desired sine/cosine relationship of the thermal differentials. Even with this inefficient geometry being used, the relationship of the two differential signals may still be approximated by $\operatorname{sine}^{3}$ and $\operatorname{cosine}^{3}$ functions (Fig. 2). This relationship means an analytical solution is possible via the simultaneous equation shown in (1)

$$
\begin{array}{r}
\theta=\arctan \left[\frac{1}{y_{2}-y_{02}} \cdot\left[-\beta \cdot\left(y_{01}-y_{1}\right) \cdot\left(y_{2}-y_{02}\right)^{2}\right]^{\frac{1}{3}}\right] \\
-c-\frac{a b s\left(y_{1}-y_{01}\right)}{y_{1}-y_{01}} \cdot \frac{\pi}{2}+\pi
\end{array}
$$

where

$$
\begin{array}{ll}
y 1 & x \text { axis output; } \\
y 01 & x \text { axis offset; } \\
y 2 & y \text { axis output; } \\
y 02 & y \text { axis offset; } \\
\beta & \text { relative amplitude of axis responses; } \\
c & \text { rotational offset of the array from } 0^{\circ} .
\end{array}
$$

Using the arctan solution of (1), the unique angular solution is found (Fig. 3) independent of air speed simultaneously varying the amplitude of both the responses.

\section{CONCLUSION}

A thin-film membrane hot wire anemometer with self heated sensing elements was fabricated and proven. This device omitted the commonly used centrally heated element [10] or peripheral heating elements [11] and instead used self heating

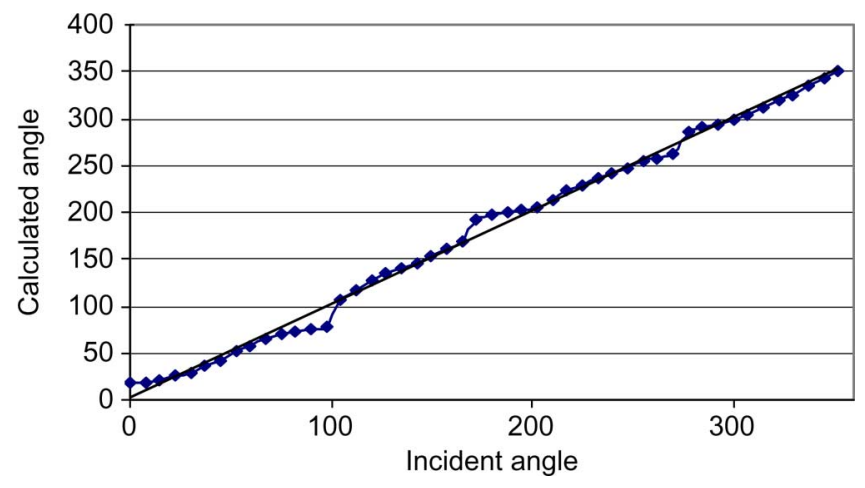

Fig. 3. Calculated solution for the sine $3 /$ consine $^{3}$ characteristic response of Fig. 2.

of the sensing elements. Device construction consisted of thermoresistive serpentine Nickel tracks patterned on a $1 \mu \mathrm{m}$ Silicon Nitride layer coating a $600 \mu \mathrm{m}$ silicon substrate that was reverse bulk etched to produce a membrane for thermal isolation of the Nickel tracks.

The self heating of the sensing elements concentrated the highest temperature regions at the sensing elements increasing the effectiveness of the forced convection heat transfer. The thermal distribution across the sensing area allowed successful calculation of the incident airflow angle to typically within $2 \%$ error for air flow velocities up to $20 \mathrm{~m} / \mathrm{s}$ for a correctly dimensioned device. Temperature differentials between opposing elements of $15^{\circ} \mathrm{C}$ were possible at low air flow velocities with a total heating power of $50 \mathrm{~mW}$ in still air at an ambient temperature of $25^{\circ} \mathrm{C}$.

\section{REFERENCES}

[1] T. Neda, K. Nakamura, and T. Takumi, "A polysilicon flow sensor for gas flow meters,” Sens. Actuators, vol. A54, pp. 626-631, 1996.

[2] U. Dillner et al., "Low power consumption thermal gas-flow sensor based on thermopiles or highly effective thermoelectric materials," Sens. Actuators, vol. A60, pp. 1-4, 1997.

[3] M. Ashauer et al., "Thermal flow sensor for liquids and gases based on combinations of two principles," Sens. Actuators, vol. 73, pp. 7-13, 1999.

[4] G. Bedo et al., "A silicon flow sensor for gases and liquids using AC measurements," Sens. Actuators, vol. 85, pp. 124-132, 2000.

[5] E. Yoon and K. Wise, "A multi-element monolithic mass flowmeter with on-chip CMOS readout electronics," in Proc. IEEE Sens. Actuators Workshop, June 1990, pp. 161-164.

[6] S. M. Sze, Semiconductor Sensors. New York: Wiley, 1994, p. 360.

[7] K. Makinwa and J. Huijsing, "A smart wind-sensor based on thermal sigma-delta modulation," in Proc. Transducers '01, Eurosensors XV, Jun. 2001.

[8] "MMW-005 data sheet," Mierij Meteo BV, 2001.

[9] K. Makinw and J. Huijsing, "A wind-sensor interface using thermal sigma delta modulation techniques," Sens. Actuators, vol. A92, pp. 280-285, 2001.

[10] N. Nguyen, "A novel wind sensor concept based on thermal image measurement using a temperature sensor array," in Proc. Eurosens. XVI, Sep. 2002.

[11] N. Nguyen, "Micromachined flow sensors-A review," Flow Meas. Instrum., vol. 8, no. 1, pp. 7-16, 1997. 